\title{
Clinical and microbiological peculiarities of nose pathology and paranasal sinuses in patients with non-hospital pneumonia.
}

\author{
Daulet Azadbek Ugli Jumanov 1, Shakhlo Khamidullaevna Bakieva ${ }^{1}$, Jamolbek Abdukakharovich Djuraev 1, , \\ Islambek Abdinasirovich Kudiyarov ${ }^{2}$ and Navruz Noryigitovich Djabbarov ${ }^{1}$
}

${ }^{1}$ Department of Otolaryngology and stomatology, Tashkent Medical Academy.

2 Department of Microbiology, Virology and Immunology, Tashkent Medical Academy.

Publication history: Received on 25 November 2020; revised on 08 December 2020; accepted on 11 December 2020

\begin{abstract}
This article presents the results of a comprehensive otorhinolaryngological and microbiological study of diseases of the nose and paranasal sinuses in patients with community-acquired pneumonia. These diseases are closely interconnected, since the upper and lower respiratory tract are a single whole, have structures and functions and mechanisms for the development of pathological conditions. The etiopathogenesis of bacterial inflammatory diseases of the upper and lower respiratory tract is based on the violation of the integrity of epithelial cells under the influence of respiratory viruses. Under the influence of the general toxic effect of the virus, phagocytosis is inhibited, immunological protection is disrupted, as a result, favorable conditions are created for microbial colonization in the nasopharynx and the further spread of infections to the paranasal sinuses and lower respiratory tract. As a result of a clinical and microbiological study, it was revealed that in community-acquired pneumonia, inflammatory diseases of the nose and paranasal sinuses such as acute and chronic rhinosinusitis, allergic and vasomotor rhinitis, curvature of the nasal septum were often encountered. To determine the nature of the microbial landsURTe of the upper and lower respiratory tract, a comparative microbiological analysis was performed from the nose and sputum. Analyzes showed that there was no significant difference in pathogenic microflora between the upper and lower respiratory tract. The main pathogen in both diseases was Streptococcus pneumoniae. Correspondence of the pathogenic microflora of the nasal cavity and lower respiratory tract when rhinosinusitis is detected in patients with community-acquired pneumonia confirms the pathogenetic relationship of inflammatory processes in these organs, as well as the need for parallel diagnosis, treatment, prevention.
\end{abstract}

Keywords:Upper and lower respiratory tract; Rhinosinusitis; Community-acquired pneumonia; Nasal cavities; Paranasal sinuses.

\section{Introduction}

The results of medical statistics convincingly indicate an increase in the number of diseases of the nose, paranasal sinuses (PNS) [1,2] and bronchopulmonary pathology [3]. The close anatomical and physiological connections between the upper and lower respiratory tract are the reason that the increase in the number of rhinosinusitis keeps pace with the increase in the number of pulmonary diseases [4] and, in particular, community-acquired pneumonia (URT).

The incidence of pneumonia in Europe and North America is 5-10 cases per 1,000 population. The mortality rate from severe pneumonia reaches $10 \%$ and continues to grow [3,5]. Most often pneumonia occurs in children, the elderly and in chronic diseases of the respiratory system. Acute respiratory viral infections (ARVI) are undoubtedly the main risk factor for community-acquired pneumonia, acute rhinosinusitis (ARS) and chronic rhinosinusitis (CRS). They develop at any period of the disease in the case of the addition of bacterial flora (streptococci, staphylococci, etc.). It is known

${ }^{*}$ Corresponding author: Djuraev Jamolbek Abdukakharovich

Department of Otolaryngology and stomatology.

Copyright (C) 2020 Author(s) retain the copyright of this article. This article is published under the terms of the Creative Commons Attribution Liscense 4.0. 
that some viruses (influenza, parainfluenza, adenovirus, respiratory syncytial virus, caronavirus, etc.) simultaneously infect epithelial cells of the upper and lower respiratory tract [13].

The etiology of community-acquired pneumonia is directly related to opportunistic microflora that colonizes the upper respiratory tract. Of the many microorganisms, only a few with increased virulence are URTable of causing an inflammatory reaction when they enter the lower respiratory tract. Among these pathogens, first of all, it is necessary to include pneumococcus. Since S.pneumoniae has more than 90 serotypes differing in antigenic properties, this microorganism can be present in the nasopharynx for years and can at any time cause the development of URT, ARS and otitis media $[3,9]$.

For some microorganisms, the development of bronchopulmonary inflammation is uncharacteristic [3]. Their isolation from sputum most likely indicates contamination of the material with the flora of the upper respiratory tract, and not about the etiological significance of these microbes. These microorganisms include Streptococcus viridans, Staphylococcus epidermidis, Enterococcus spp., Neisseria spp., Candida spp. It is believed that in almost any ARVI, the paranasal sinuses are involved in the process to one degree or another $[10,12]$.

Acute rhinosinusitis in 95\% of cases is caused by viruses, 5-7 days after the onset of ARVI, a bacterial process develops $[6,7]$. Under the influence of the virus on the ciliated epithelium of the nasal cavity and paranasal sinuses, epithelial cells lose cilia, the epithelium becomes loose, and edema of the mucous membrane develops. As a result of these processes, as well as the active release of pro-inflammatory mediators, an inflammatory reaction develops. The consequence of this is a violation of aeration of the sinuses, inactivation of mucociliary clearance and the accumulation of serous exudate in the lumen of the sinuses. A decrease in the rate of mucociliary transport allows prolonging the contact time of pathogenic bacteria with the mucous membrane and contributes to bacterial infection $[8,12,13]$.

The nasal cavity and paranasal sinuses are a highly organized structure, with a delicate and complex regulation mechanism, which have many specific functions. Such a morphofunctional system provides the first barrier to infection. A subtle functional connection of the nasal cavity and paranasal sinuses with other organs and systems, primarily with the bronchopulmonary system, is obvious.

\section{Material andmethods}

In total, 80 patients with community-acquired pneumonia who were hospitalized in the pulmonary department of the multidisciplinary clinic of the Tashkent Medical Academy were examined. Among the surveyed there were 32 men and 48 women aged 18 to 65 years (the average age in the group was $45.6 \pm 8.75$ years). In all patients, complaints and history of the development of the disease were clarified in detail, the general condition of the patients was examined.

When collecting the anamnesis, the timing of the onset of the disease was specified, the timing of the occurrence of relapses, their relationship with infectious diseases of the upper respiratory tract, as well as the presence of concomitant diseases of other organs were taken into account. Of the research methods, the endoscopic method of studying the ENT organs was used, while all the formations of the nasal cavity were carefully examined. To determine the prevalence of the inflammatory process, all patients underwent 3D X-ray and computed tomography of the PNS.

Special attention was paid to changes on the part of the ENT organs and, if necessary, other specialists were consulted. The microbiological characteristics of the upper and lower respiratory tract in patients with community-acquired pneumonia were studied using bacteriological methods. Sterile applicators were inserted into the middle nasal passage and swabs were taken to determine the pathogenic microflora of the nose and PNS. The applicator was placed in a test tube with a transport medium and the last name, first name and date of birth were indicated. To collect sputum, the patient was stimulated to cough reflex by pressing on the root of the tongue. The sputum was collected with a spatula in a sterile container. Analysis of pathological discharge from the middle nasal passage and sputum was carried out in the bacteriological laboratory of the multidisciplinary clinic of the Tashkent Medical Academy. Bacteriological inoculation was carried out on enriched selective nutrient media of the firm "bio Merieux" (France).

Purpose of the study: study of the prevalence and characteristics of pathogenic microflora in diseases of the nose and paranasal sinuses in patients with community-acquired pneumonia, optimization of diagnosis, treatment and prevention of community-acquired pneumonia with bacterial rhinosinusitis. 


\section{The discussion of the results}

As a result of a comprehensive otorhinolaryngological examination, a number of concomitant ENT diseases were revealed in patients with community-acquired pneumonia. ENT organs diseases were detected in $100 \%$ of patients (table 1).

Table 1 Concomitant diseases of ENT organs in patients with community-acquired pneumonia

\begin{tabular}{|l|l|l|}
\hline Accompanying illnesses & \multicolumn{2}{|l|}{ Number of patients } \\
\hline & $\mathrm{P}$ & $\%$ \\
\hline Acute rhinosinusitis & 30 & 37,5 \\
\hline Chronic rhinosinusitis & 16 & 20,0 \\
\hline Acute pharyngitis & 34 & 42,5 \\
\hline Chronic pharyngitis & 18 & 22,5 \\
\hline Curvature of the nasal septum & 18 & 18,8 \\
\hline Allergic and vasomotor rhinitis & 22 & 27,5 \\
\hline Chronic tonsillitis & 16 & 20,0 \\
\hline Cyst PNS & 6 & 7,5 \\
\hline Sensorineural hearing loss & 5 & 5,8 \\
\hline Chronic otitis media & 3 & 3,8 \\
\hline
\end{tabular}

Among the total number of concomitant diseases of ENT organs, it is worth noting the rather frequent occurrence of acute and chronic rhinosinusitis, pharyngitis, allergic and vasomotor rhinitis. Considering the average age of patients, they often have chronic diseases of the ENT organs. In 46 (57.5\%) patients, subjective complaints (difficulty in nasal breathing, nasal discharge, headache, hyposmia) and objective symptoms (hyperemia and edema of the nasal mucosa, nasal discharge, pain on palpation of the projection of the PNS) were revealed. for inflammatory diseases of the nasal mucosa and PNS.

To assess the severity of disturbing nasal complaints, a visual analogue scale (VAS) was used, which implies division into mild, moderate and severe severity. The patient, on his own, should note on the line, conditionally divided into 10 sections, how much the symptoms of rhinosinusitis bother him, with from 0 to 4 mild, and from 5 to 10 moderate / severe. As a result, $20(25.0 \%)$ patients from the total number of examined patients, using the VAS scale, characterized their nasal complaints as moderate / severe, 26 (32.5\%) - mild. 3D radiography and computed tomography of PNS were performed in all 80 patients. X-ray changes in the PNS were recorded with mucosal thickening of more than 6 mm. Xray changes were detected in $25(31.25 \%)$ patients. In three patients, a total decrease in pneumatization of all PNSs was revealed, in two patients - right-sided hemisinusitis, in 11 - right-sided maxillary ethmoiditis, in 15 - left-sided haimoroetmoiditis. X-ray changes detected in patients are presented in Table 2.

Table 2 Results of X-ray examination of PNS

\begin{tabular}{|l|l|l|l|l|}
\hline \multicolumn{2}{|c|}{} & Total & Subtotal & Liquid level \\
\hline \multirow{3}{*}{ Maxillary sinus } & Right & 1 & 12 & 3 \\
\cline { 2 - 5 } & Left & 5 & 12 & 1 \\
\hline \multirow{3}{*}{ Ethmoidal sinus } & Right & 2 & 6 & - \\
\cline { 2 - 5 } & Left & 3 & 7 & - \\
\hline \multirow{3}{*}{ Frontal sinus } & Right & 2 & 2 & - \\
\cline { 2 - 5 } & Left & 1 & 1 & - \\
\hline \multirow{2}{*}{ Sphenoidal sinus } & Right & 1 & 3 & - \\
\cline { 2 - 5 } & Left & 1 & 2 & - \\
\hline
\end{tabular}

It should be noted that X-ray changes in PNS were detected in all 20 (27.7\%) patients who described their condition as moderate / severe. Among the patients who characterized their condition as mild, radiological changes (thickening of 
the mucous membrane more than $6 \mathrm{~mm}$ ) were detected in 5 patients. As a result of examining swabs taken from the nasal cavity, microflora was obtained in 46 (100\%) patient. A total of 71 microorganisms were identified. Mixed flora was obtained in $22(47.8 \%)$ of 46 patients, the maximum number of pathogens in the association was 3. Gram-positive facultative anaerobes were detected in $46(64.7 \%)$ bacterial strains, the majority were microorganisms of the genus Streptococcus and Staphylococcus 17 (22.0\%) gram-negative facultative anaerobes. Gram-negative aerobes were detected in the amount of 2 (2.5\%) strains (Neisseria spp.). Fungal flora isolated in 6 (7.8\%) patients, more often isolated in association with bacterial pathogens (table 3).

Table 3 Microorganisms isolated from patients with rhinosinusitis $(p=54)$

\begin{tabular}{|c|c|c|c|c|}
\hline \multirow[t]{2}{*}{ Microorganisms } & \multicolumn{2}{|c|}{ Upper respiratory the way } & \multicolumn{2}{|c|}{ Lower respiratory tract } \\
\hline & number of strains & $\%$ & number of strains & $\%$ \\
\hline Streptococcus pneumoniae & 18 & 39,1 & 20 & 43,5 \\
\hline Haemophilus influenza & 9 & 19,5 & 6 & 13,0 \\
\hline Staphylococcus aureus & 7 & 15,2 & 6 & 13,0 \\
\hline Streptococcus viridans & 7 & 15,2 & 3 & 0 \\
\hline Streptococcus pyogenes & 5 & 10,8 & 7 & 15,2 \\
\hline Staphylococcus haemolyticus & 5 & 10,8 & 3 & 5,5 \\
\hline Staphylococcus epidermidis & 4 & 8,7 & 2 & 4,3 \\
\hline Klebsiella pneumonia & 4 & 8,7 & 6 & 13,0 \\
\hline Candida spp. & 6 & 11,1 & 2 & 4,2 \\
\hline Neisseria spp. & 2 & 4,3 & - & 0 \\
\hline Proteus mirabilis & 1 & 2,1 & - & 0 \\
\hline Escherichia coli & 2 & 4,3 & 2 & 4,3 \\
\hline Entorococcusfaecalis & 1 & 2,1 & 2 & 4,3 \\
\hline In total: & 71 & - & 59 & - \\
\hline
\end{tabular}

Bacteriological examination of sputum taken from 46 patients revealed 59 strains of microorganisms. The results of a microbiological study of sputum culture are presented in Table 3. The growth of microorganisms in the sputum culture was observed in $36(78.2 \%)$ patients, in 10 (21.7\%) patients microorganisms were not detected. Mixed microflora was detected in $6(13.0 \%)$ patients, the maximum number of pathogens in the association was 2. Gram-positive facultative anaerobes were identified $41(69.5 \%)$ bacterial strains, the majority, as in the results of seeding from the middle nasal passage, amounted to microorganisms of the genus Staphylococcus and Streptococcus. The growth of 11 (18.6\%) gramnegative facultative anaerobes was obtained. Gram-negative aerobes were detected in the amount of 2 (3.0\%) strains (Moraxella catarrhalis). Fungal flora isolated in $5(7.7 \%)$ patients, more often isolated in association with bacterial pathogens.

\section{Conclusion}

After examining 80 patients with URT, it is worth noting the rather high prevalence of complaints and symptoms characteristic of inflammatory diseases of the nasal mucosa, in particular rhinosinusitis. In our study, 46 (67.5\%) patients had symptoms of ARS and CRS. X-ray changes were detected in $25(31.25 \%)$ patients. In many ways, the etiopathogenesis of rhinosinusitis is similar to URT. The microflora obtained from sputum and the middle nasal passage is almost identical in patients with URT. As a result of examining smears taken from the nasal cavity, microflora was obtained in 46 (67.5\%) patients, growth was noted in all patients. A total of 71 microorganisms were identified. Bacteriological examination of sputum taken from patients revealed 59 microorganisms, no growth was noted in 10 $(21.7 \%)$ patients. The main causative agent in acute and chronic rhinosinusitis in patients with URT was Streptococcus pneumoniae (39.1\% and $43.5 \%$, respectively). Thus, based on the data obtained, it can be concluded that inflammatory diseases of the nose and PNS are interrelated with URT. Early diagnosis and concurrent treatment of rhinosinusitis with 
URT gives us a quick and complete recovery of patients and reduces the development of complications. Timely and effective treatment of inflammatory diseases of the upper respiratory tract after an acute respiratory viral infection is considered one of the preventive measures of URT.

\section{Compliance with ethical standards}

\section{Acknowledgments}

We express our blogging to the colleagues of the editorial board of the journal, which provided us with the publication of our scientific work in this journal.

\section{Disclosure of conflict of interest}

Authors unanimously agree with the publication of this scientific work.

\section{References}

[1] Djuraev JA. et al. Results of Allergological and Immunological Research in Patients with PolipoidRhinosinusitis //Asian Journal of Immunology. 2020; 34-40.

[2] Autio TJ, Tapiainen T, Koskenkorva T. et al. The role of microbes in the pathogenesis of acute rhinosinusitis in young adults // Laryngoscope. 2014; 125.

[3] Gwaltney JM Jr, Phillips CD, Miller RD, Riker DK. Computed tomographic study of the common cold // N Engl J Med. 1994; 330: 25-30.

[4] Smith SS, Ference EH, Evans CT, et al. The prevalence of bacterial infection in acute rhinosinusitis: A systematic review and meta-analysis // Laryngoscope. 2015; 125: 57-69.

[5] Passali D, Loglisci M, Passali GC.A prospective open-label study to assess the efficacy and safety of a herbal medicinal product (Sinupret) in patients with acute rhinosinusitis. ORL J OtorhinolaryngolRelat Spec. 2015; 77(1): 27-32.

[6] Lina G. et al. Bacterial competition for human nasal cavity colonization: role of staphylococcal agr alleles //Applied and environmental microbiology. 2003; 69(1): 18-23.

[7] Khasanov US, Vokhidov UN, Djuraev JA. State of the nasal cavity in chronic inflammatory diseases of the nose and paranasal sinuses in patients with myocarditis //European science. 2018; 9(41).

[8] Djuraev JA, Khasanov US, Vokhidov UN. The prevalence of chronic inflammatory diseases of the nose and paranasal sinuses in patients with myocarditis //European Science Review. 2018 (5-6); 147-149.

[9] VOHIDOV UN, et al. Current issues of the treatment of chronic polypousrhinosinusitis //Journal of Biomedicine and Practice. 2020 (5); 2.

[10] Normurodov BK, et al. Prevalence and structure of purulent inflammatory diseases of the maxillofacial area //Central Asian Journal of Medicine. 2020 (1); 116-130.

[11] UN Vokhidov, et al. The local immunity in the tissues of various forms of nasal polyps. ALLERGY. Vol. 71. 111 River ST, Hoboken 07030-5774, NJ USA: Wiley-Blackwell. 2016.

[12] Жамолбек ДА.,Улугбек ХС, Улугбек ВН. Morphological characteristics of the mucous membrane of the nose and paranasal sinuses in case of chronic rhinosinusitis //Uzbek medical journal. 2020 (1); 5.

[13] Ходжанов Ш. Х. и др. Clinical and morphological characteristics of anthrochanalpolyps //Uzbek medical journal. 2020 (1); 6.

[14] Шаумаров А. З.,Шайхова Х. Э., Джураев Ж. А. Assessment of the influence of nose tamponade on quality of life in the early postoperative period after septoplasty //Uzbek medical journal. - 2020 (1); 5. 